\title{
CORRECTION
}

View Article Online

View Journal I View Issue

Check for updates

Cite this: J. Mater. Chem. A, 2018, 6 , 21618

DOI: $10.1039 / \mathrm{c} 8 \operatorname{ta} 90244 \mathrm{e}$

www.rsc.org/MaterialsA

\section{Correction: Efficient non-fullerene organic solar cells employing sequentially deposited donor-acceptor layers}

\author{
Jiangbin Zhang, ${ }^{\text {ab }}$ Bin Kan, ${ }^{c}$ Andrew J. Pearson, ${ }^{\mathrm{a}}$ Andrew J. Parnell, \\ Joshaniel F. K. Cooper, ${ }^{e}$ Xiao-Ke Liu, ${ }^{\text {af }}$ Patrick J. Conaghan, ${ }^{a}$ Thomas R. Hopper, ${ }^{b}$ \\ Yutian Wu, ${ }^{a}$ Xiangjian Wan, ${ }^{c}$ Feng Gao, ${ }^{f}$ Neil C. Greenham, ${ }^{a}$ Artem A. Bakulin, ${ }^{b}$ \\ Yongsheng Chen ${ }^{\star c}$ and Richard $\mathrm{H}$. Friend*a
}

Correction for 'Efficient non-fullerene organic solar cells employing sequentially deposited donor-acceptor layers' by Jiangbin Zhang et al., J. Mater. Chem. A, 2018, 6, 18225-18233.

In the published article, the affiliation for author Yutian $\mathrm{Wu}$ was incorrectly shown as affiliation ' $\mathrm{b}$ '. The correct affiliation is affiliation ' $a$ ', as shown in the amended author list here.

The Royal Society of Chemistry apologises for these errors and any consequent inconvenience to authors and readers.

${ }^{a}$ Cavendish Laboratory, University of Cambridge, JJ Thomson Avenue, Cambridge CB3 OHE, UK. E-mail: rhf10@cam.ac.uk ${ }^{b}$ Department of Chemistry, Imperial College London, London SW7 2AZ, UK

'The Centre of Nanoscale Science and Technology, Key Laboratory of Functional Polymer Materials, State Key Laboratory and Institute of Elemento-Organic Chemistry, College of Chemistry, Nankai University, Tianjin, 300071, China. E-mail: yschen99@nankai.edu.cn

${ }^{d}$ Department of Physics \& Astronomy, The University of Sheffield, Hicks Building, Hounsfield Road, Sheffield S3 7RH, UK

'ISIS Neutron and Muon Source, Science and Technology Facilities Council, Rutherford Appleton Laboratory, Didcot, OX11 OQX, UK

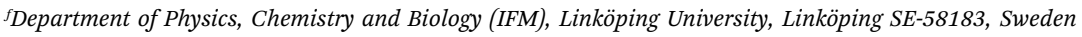

